\title{
A remote controlled freeze corer for sampling unconsolidated surface sediments
}

\author{
A. F. Lotter ${ }^{1,4}$, I. Renberg ${ }^{2}$, H. Hansson ${ }^{3}$, R. Stöckli ${ }^{1}$ and M. Sturm ${ }^{1}$ \\ 1 Swiss Federal Institute for Environmental Science and Technology (EAWAG), \\ CH-8600 Dübendorf, Switzerland \\ 2 Department of Environmental Health, Umeå University, S-90187 Umeå, Sweden \\ 3 HTH Teknik, Vårvägen 37, S-95149 Luleå, Sweden \\ ${ }^{4}$ Geobotanical Institute, University of Bern, Altenbergrain 21, CH-3013 Bern, Switzerland
}

Key words: Coring methods, freeze coring, soft bottom sediments, laminated sediments.

\begin{abstract}
A new coring device is presented which allows the recovery of loose watery surface sediments and the water/sediment interface by in situ freezing, resulting in well preserved samples. The instrument consists of a tripod with adjustable legs, a hydraulic system, an insulated thermos (with two electrical pumps), and a wedge-shaped freeze box. Alcohol chilled with dry ice is the freezing agent. The corer can be deployed from a boat or a raft and permits recovery of undisturbed surface sediment sections up to $100 \mathrm{~cm}$ long in deep waters. The corer is particularly useful for sampling varved sediments.
\end{abstract}

\section{Introduction}

Studies of recent environmental pollution and climatic change, from lacustrine or marine deposits, require high-resolution sampling of the sediment record. Investigations of annually laminated sediments allow a high temporal resolution of single seasons or single years. Furthermore, the absolute chronology gained from these varved sediments is independent of physical dating methods such as ${ }^{137} \mathrm{Cs},{ }^{210} \mathrm{~Pb}$, or ${ }^{14} \mathrm{C}$.

Sampling of the topmost, unconsolidated sediment of soft bottoms is commonly carried out by means of short gravity corers (e.g. Blomqvist and Abrahamsson, 1985; Wright, 1990; Glew, 1991; Renberg, 1991). However, the reliability of this sampling method has been questioned due to incomplete recovery resulting from a potential hydraulic shock wave or deficient entry of the sediment into the coring tube because of internal friction (see e.g. Hongve and Erlandsen, 1979; Anderson et al., 1987; Parker and Sills, 1990; Blomqvist, 1991; Crusius and Anderson, 1991; Cornett and Chant, 1993). Smearing of sediment against the inside of the coring 
tube may render direct visual inspection impossible (Blomqvist, 1991; Chant and Cornett, 1991). Moreover, cutting the core tube longitudinally can result in either loss or homogenisation of the topmost watery sediment. Freezing of sections of gravity cores has been applied successfully in some lakes with highly minerogenic sediments (Pollingher et al., 1992). In highly organic sediments methane ebullition often occurs when the core is ascended to the water surface. Such gas ebullition may destroy or homogenize the laminations.

Freezing of surface sediments in situ is a successful method for high-resolution studies of recent lake sediments, particularly for the analysis of varved lake sediments. Different types of freeze corers have been described: tube-shaped (Shapiro, 1958; Wright, 1980; Miskimmin et al., 1996), letter-box shaped (Huttunen and Meriläinen, 1978), and wedge-shaped (Renberg, 1981) containers. The thin, wedgeshaped type produces the least disturbance during sediment penetration. All these devices are fairly simple to use and easy to handle in the field. From a technical point of view this method is actually not a coring, but rather an in situ freezing of sediment to the surface of a container filled with a freezing agent. Commonly, a mixture of dry ice (solid $\mathrm{CO}_{2}$ ) and a liquid with a low freezing point such as alcohol is used as a cooling agent. Liquid nitrogen with a much lower temperature than dry ice $\left(-195^{\circ} \mathrm{C}\right.$ vs. $-78^{\circ} \mathrm{C}$ at atmospheric pressure) is occasionally used (Pachur et al., 1984; Klee and Schmidt, 1987), although its handling is more dangerous.

Freeze-coring is traditionally carried out from ice-covered, shallow $(<30 \mathrm{~m})$ lakes. In many temperate regions such as lowland Central Europe, lakes rarely freeze and it is therefore necessary to deploy the corers from a boat or raft. One difficulty with freeze coring is, that it is difficult to control the depth of penetration into the sediment, which is a function of the weight of the corer and the consistency of the sediment. It may occasionally occur that the corer tilts or penetrates too deeply into the sediment, thereby not sampling the water-sediment interface.

Other problems arise with these conventional freeze corers when used in deep lakes $(>30-40 \mathrm{~m})$. Lake water will inevitably freeze to the surface of the container and form a crust upon descending the water column. This makes the corer thicker, thus enhancing sediment disturbance at penetration, and, more importantly, a substantial amount of dry ice is consumed while the device is lowered to the lake bottom.

Renberg and Hansson (1993) presented an improved freeze corer, which separated the dry-ice/alcohol container from the freezing wedge. Once the corer has penetrated the sediment, an electrical pump circulates chilled alcohol through the wedge. Compared to conventional freeze coring devices, this construction overcomes the ice crust formation problem, and allows the construction of a very thin freeze wedge.

\section{New device}

Following the ideas of Renberg and Hansson (1993) we have further developed the pump freeze corer in order to make this coring system usable in areas without a seasonal ice-cover. The new device can be used in lakes and shallow seas to provide frozen cores of recent sediments up to $100 \mathrm{~cm}$ long. The main modifications include 


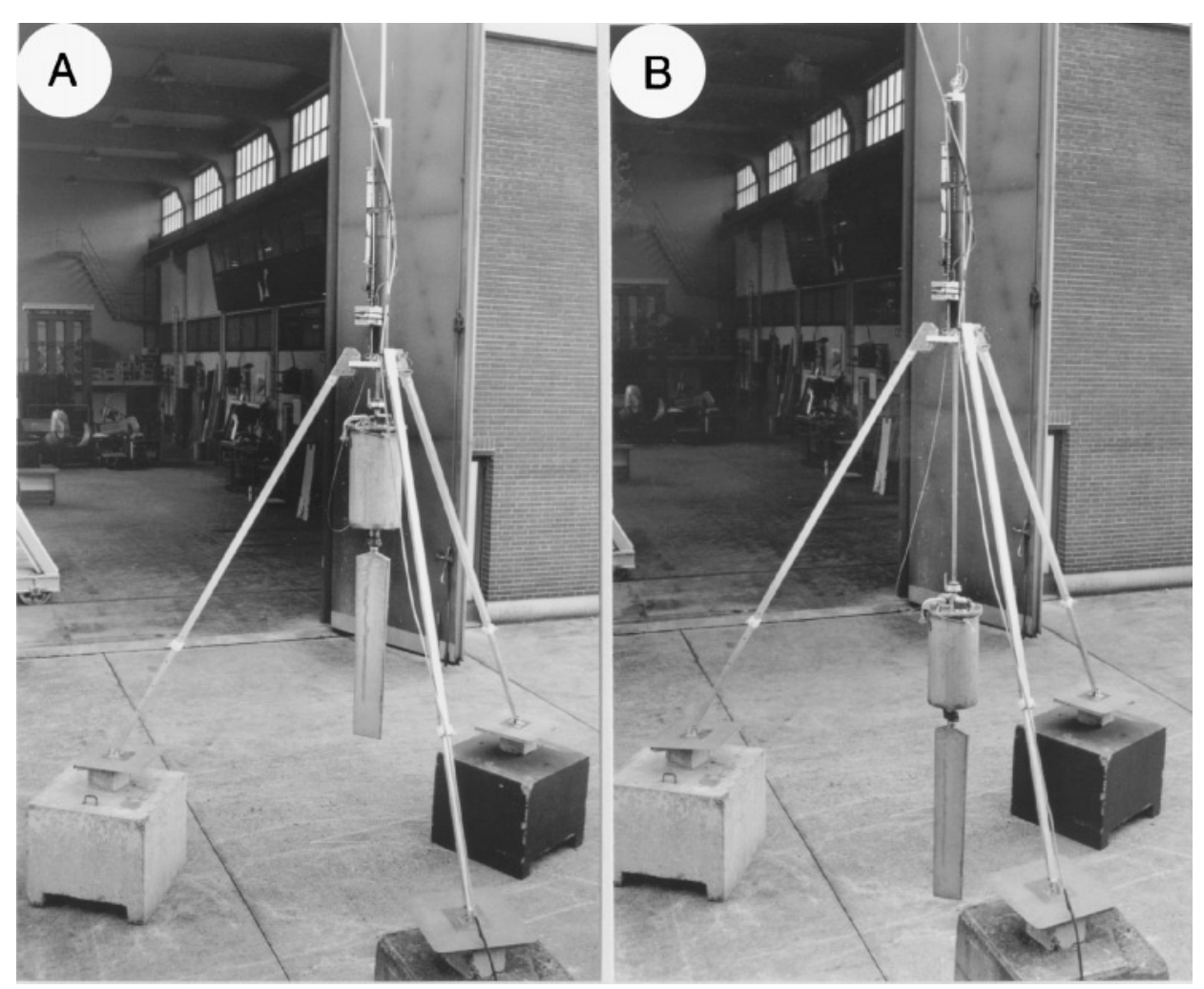

Figure 1. Overview on the freeze corer. A. Position at the sediment surface. B. Operational position for sediment freezing in situ

a tripod to stabilize the device at the sediment surface, and a hydraulic system for controlled lowering of the corer into the sediment (see Fig. 1). All components can be disassembled and transported in a minibus. The total weight of the new device is ca. $115 \mathrm{~kg}$. Detailed technical drawings of this new device may be obtained from the first author.

Once the tripod has reached the sediment surface, the hydraulic system is triggered by an electrical valve, allowing a maximum lowering of the wedge by $120 \mathrm{~cm}$ (see Figs. 1 and $3 \mathrm{~B}$ ). This allows the freeze wedge to penetrate the sediment in a steady and slow motion. A gyro-joint (see Fig. $2 \mathrm{~A}$ ) ensures that the corer is always in a vertical position. The tripod legs are made of aluminium, each weighing $6 \mathrm{~kg}$. At their lower ends aluminium plates $(40 \times 40 \mathrm{~cm})$ help to stabilize the device at the sediment surface and prevent its sinking into the sediment. The leg length can be adjusted telescopically between 245 and $345 \mathrm{~cm}$, resulting in a range of 220 to $280 \mathrm{~cm}$ between the gyro-joint and the sediment surface. The cylindrical stainless steel thermos ( $32 \mathrm{~cm}$ diameter, $58 \mathrm{~cm}$ height, $52 \mathrm{~kg}$ weight, see Fig. 1 and 3A) is double-walled, and insulated between the walls with polyurethane foam. It has a volume of 40 litres and contains two automobile fuel pumps that transport the 

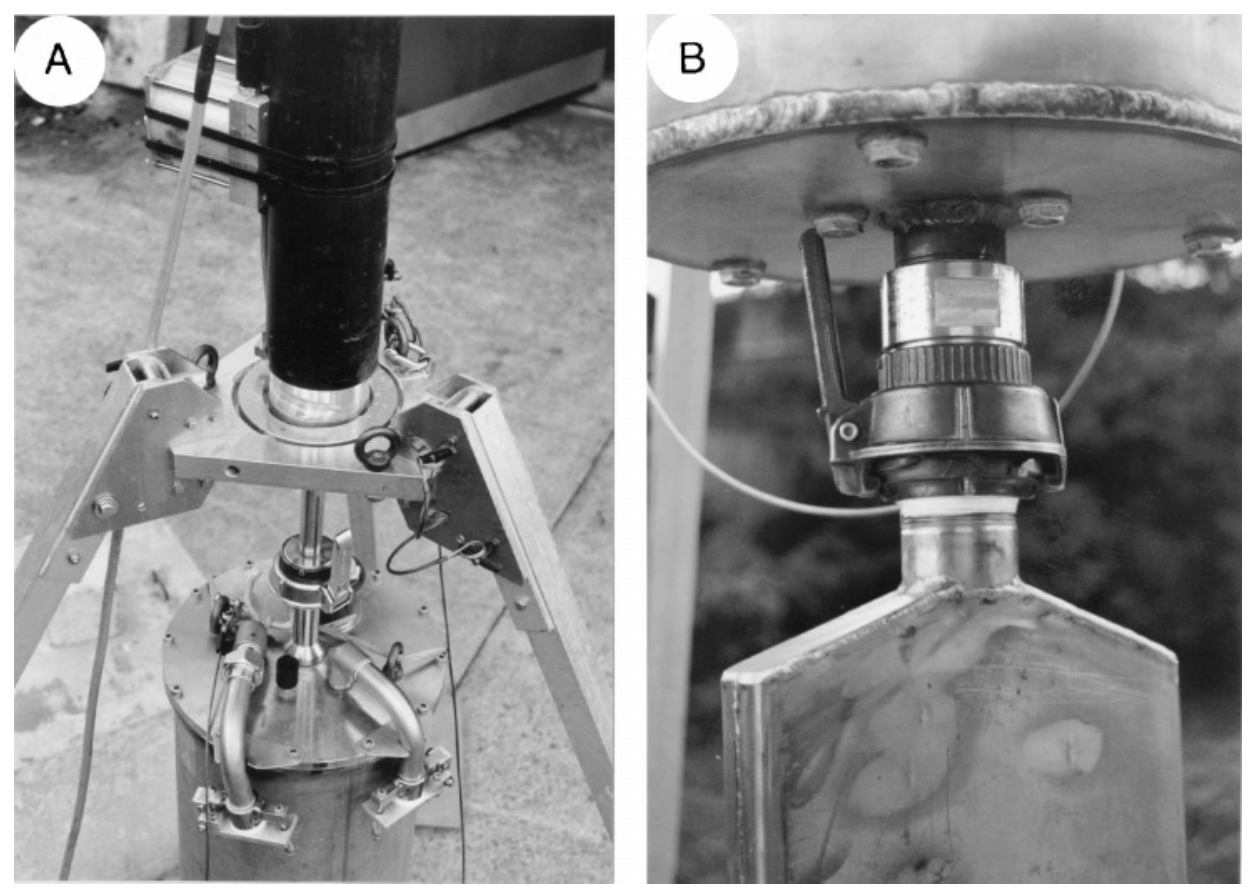

Fig. 2. Details of the freeze corer. A. Gyro-joint of tripod, thermos with two valves. B. Detail of thermos and its coupling to the freeze wedge

freezing agent from the thermos to the wedge. Two valves mounted on the lid of the thermos (see Fig. $2 \mathrm{~A}$ ) allow the release of $\mathrm{CO}_{2}$ gas at excess pressure. To enhance penetration of the freeze wedge into consolidated or minerogenic sediments, additional weights can be attached to the thermos. The thermos is attached to the rod of the lowering hydraulic system ( $300 \mathrm{~cm}$ long, $33 \mathrm{~kg}$ weight) by a coupling commonly used for large hoses (see Fig. 2 A). The same type of joint is used to attach the freeze wedge to the thermos (see Fig. 2 B). The freeze wedge ( $8 \mathrm{~kg}$ weight when empty) has a length of $110 \mathrm{~cm}$ and an area of $20 \times 4.5 \mathrm{~cm}$ at the upper end and $18 \times 1 \mathrm{~cm}$ at the lower end. The 24 Volt power supply is provided by two $12 \mathrm{~V}$ automobile batteries located on the boat, and the electrical power is transmitted to the hydraulic valve and to the pumps by a cable.

\section{Use of the freeze corer}

It has been found appropriate to stabilize the boat with three anchors, before the different parts of the corer are assembled and the device is attached to a $5-7 \mathrm{~mm}$ nylon rope. Then 25-30 litres of alcohol (ethanol or methanol, see Renberg and Hansson, 1993) and 10-15 kg of dry ice are added to the thermos. The pumps are turned on for a minute in order to test them and to fill the wedge with alcohol. Then the corer is lifted into the water and lowered to ca. $2 \mathrm{~m}$ above the sediment surface, 

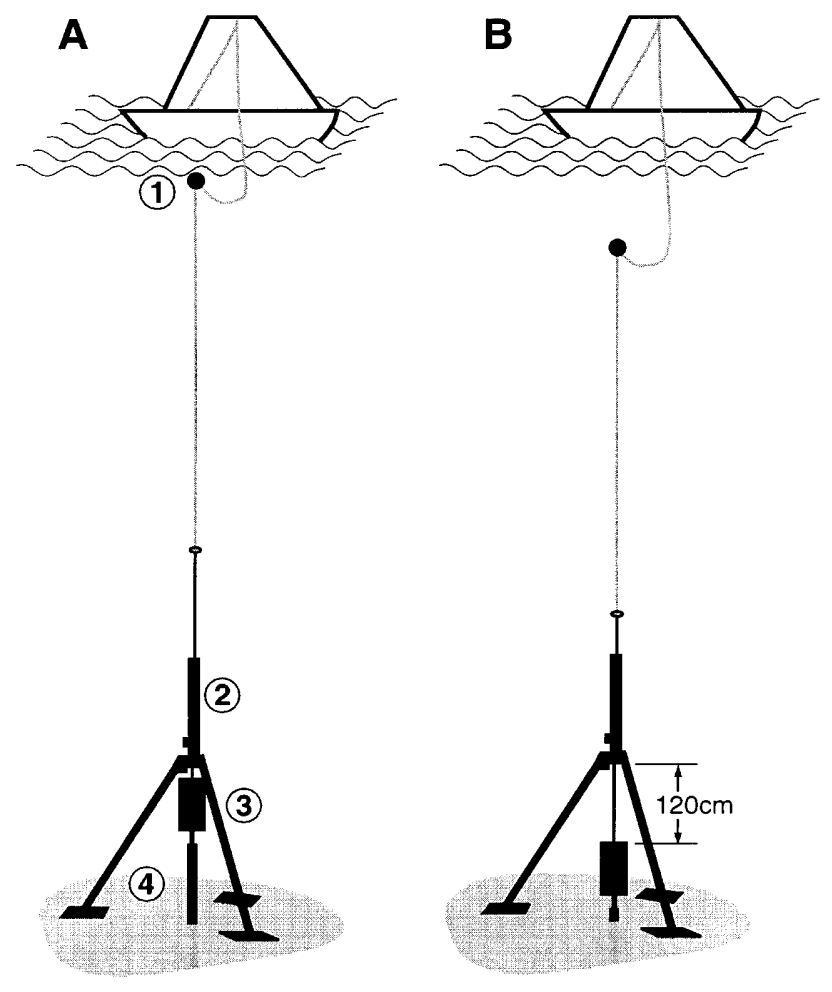

Figure 3. Schematic sketch of the operation of the freeze corer from a boat. A. Lowering to the sediment surface. 1 Surface buoy; 2 Tripod with hydraulic system; 3 Thermos; 4 Freeze wedge. B. Triggering of the hydraulic system and subsequent lowering of the freeze wedge into the surficial sediment. Maximum travel of the hydraulic system is $120 \mathrm{~cm}$

where it is left until spinning or sideway movements ceased. It is then lowered to the sediment surface. The whole operation is monitored by echo-sounding. The electric supply cable is attached to the supporting rope by specially designed clamps at intervals of $15-20 \mathrm{~m}$. Once the corer has reached the sediment surface a buoy (ca. $10 \mathrm{~kg}$ buoyancy) is attached to the rope and cable at the water surface to prevent them from tilting the corer. Then the electrical valve of the hydraulic lowering cylinder is opened, and the thermos and wedge sink by their own weight (see Figs. 1 and 3). The freeze wedge penetrates the sediment in a slow and constant vertical movement. The descent of the hydraulic system can be observed by echo-sounding as well as by the descending surface buoy. Once the hydraulic system has come to a stop, the valve is closed again, and the pumps are switched on to circulate the chilled alcohol. After 20-30 minutes of freezing the corer is hauled up to the surface (Fig. 4). Before the power is turned off and the freeze wedge detached from the thermos, the unfrozen sediment is scraped off the frozen sediment crust with a knife or spatula. This facilitates later cleaning of the frozen sediment crust. The alcohol is poured out of the freeze wedge. After the wedge has warmed to ambient 


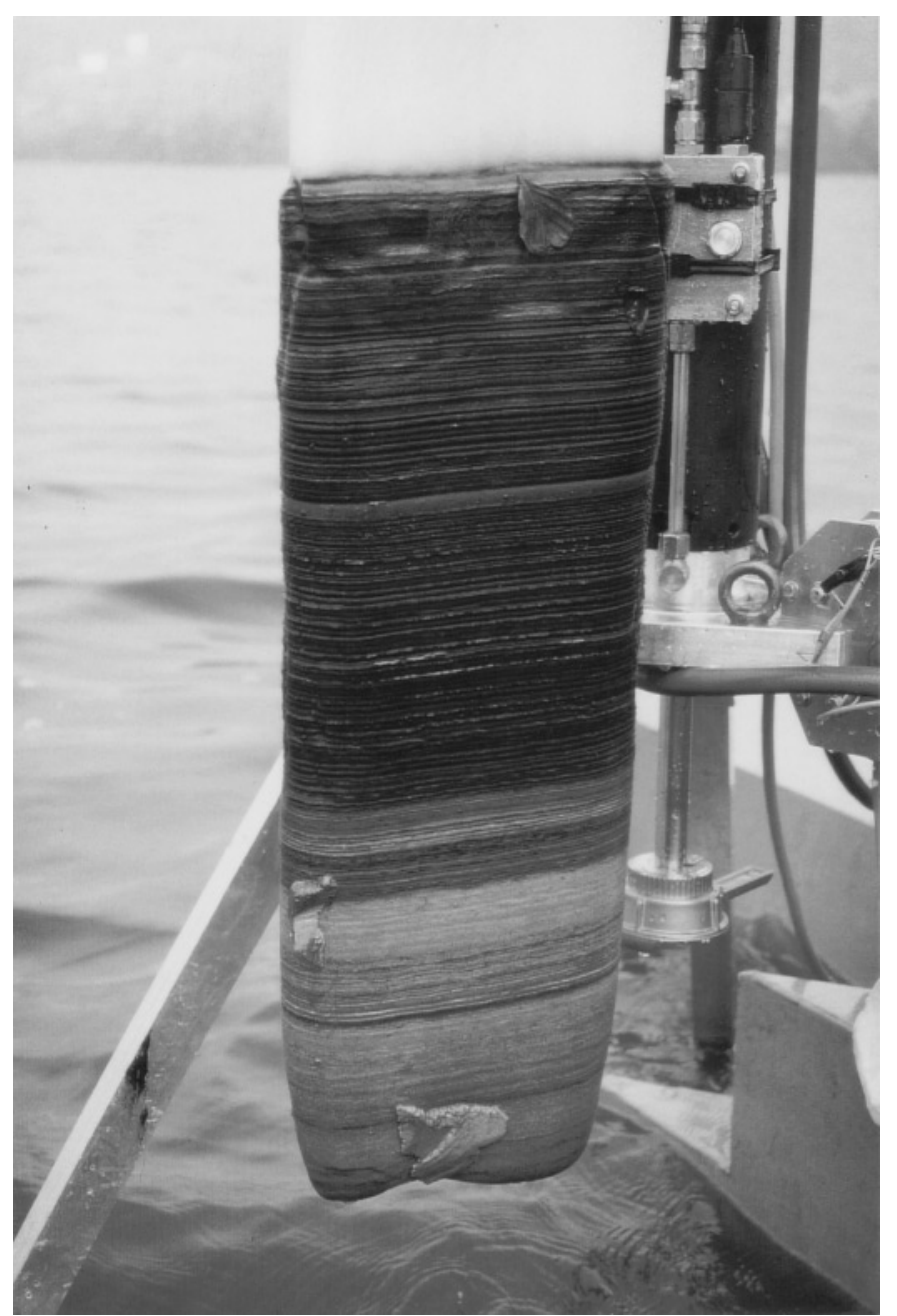

Figure 4. Wedge with frozen sediment and sediment-water interface from the deepest part of Baldeggersee $(66 \mathrm{~m})$, Switzerland

temperature, it is filled with warm water and the frozen sediment crust is detached. The sediment crust is filled with dry ice, wrapped in plastic foil, and transported in a cold box to a laboratory for storage in a cold room at temperatures of $-10^{\circ} \mathrm{C}$ to $-20^{\circ} \mathrm{C}$. Airtight wrapping is essential when storing, as the frozen sediment freezedries quickly in the cold room.

For use in deep waters some further adaption had to be made, as the temperature in the freeze wedge increases with increasing pressure. For these conditions we have exchanged one of the gas valves on the thermos with a hose attached to the rope and electric cable, which reaches water depths $<40 \mathrm{~m}$. This results in a lower pressure inside the thermos. However, in order to operate under pressure differences of 2-4 bar the freezing wedge has to be manufactured of rigid stainless steel. 


\section{Sediment preparation}

The field procedure results in two large slabs of frozen sediment $(20 \mathrm{~cm}$ width, up to $100 \mathrm{~cm}$ length, up to $5 \mathrm{~cm}$ thickness). Their thickness is the same at the sediment/water interface as at the bottom. The sediment is sampled in a cold room at temperatures of $-8^{\circ} \mathrm{C}$ to $-10^{\circ} \mathrm{C}$. First, the frozen sediment crust is sawed longitudinally into two parts (see Renberg, 1981). This can be done with a wood saw manually or with an electrical saw. Care must be taken, however, not to break the frozen sediment. To remove contamination, both front and back surfaces are

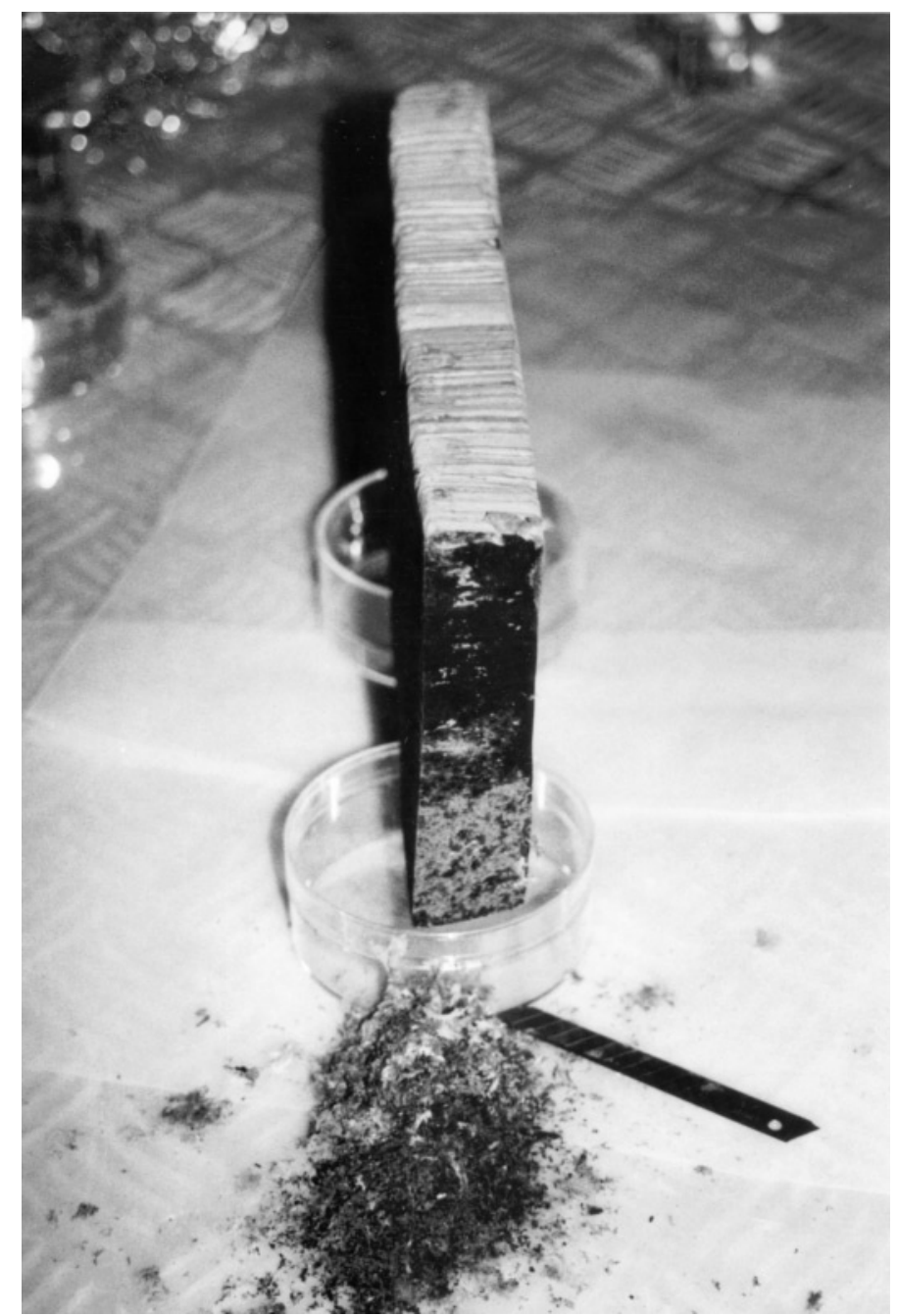

Figure 5. Sampling by scraping single seasonal layers of Baldeggersee sediment with a paper knife blade 
cleaned with a wood plane or a metal scraper. Sediment for a variety of analyses from the same core is now available.

The new freeze corer has been used for analyses of varved sediments in deep Swiss lakes by the following procedure (see also Lotter et al., 1997; Lotter, in press). After the core is photographed, a $5 \mathrm{~cm}$ wide slab is sawed vertically from the core, freeze-dried, and then impregnated with an epoxy resin (e.g. Lamoureux, 1994). Petrographic thin sections $25-30 \mu \mathrm{m}$ thick prepared from these impregnated sediments are essential for microstratigraphical identification of varves, for distinguishing allochthonous deposits such as turbidites, and for building up a varve chronology (Merkt, 1971). The position, boundaries, and age of each single varve is then marked on a 1:1 core photograph. In the cold room these photographs are indispensable for the exact sampling of annual or even seasonal layers. Depending on the amount of sample material needed, a block $10-15 \mathrm{~cm}$ wide is sawed out of the core. From this block each annual or seasonal layer is scraped off with a papercutter blade (Fig. 5). The scraped sediment is collected on plastic foil underlaying the sediment block (see Fig. 5), transferred to a pre-weighed sample box, weighed, and eventually freeze-dried for further analyses. Water content of the sediment is then calculated, and the dry accumulation per year or season can be estimated by dividing the dry weight by the known surface area of the sampled sediment (see also Segerström and Renberg, 1986). The freeze-dried samples can be used for geochemical, isotopic, and biostratigraphical analyses (see Schaller et al., 1997; Lotter, in press).

\section{ACKNOWLEDGEMENTS}

We should like to thank R. Berger, EAWAG workshop, for his help with constructing and testing the corer. H. E. Wright, B. Wehrli and three anonymous reviewers made valuable comments on earlier versions of the manuscript. This work was supported by Swiss National Science Foundation through National Research Program 31 project 4031-33147 and Priority Programme Environment project 5001-34876 and the Swedish Natural Science Research Council. This is a contribution to the IGCP 374 project "Palaeoclimatology and palaeoceanography from late Quaternary and Holocene laminated sediments".

\section{REFERENCES}

Anderson, R. F., S. L. Schiff and R. H. Hesslein, 1987. Determining sediment accumulation and mixing rates using ${ }^{210} \mathrm{~Pb},{ }^{137} \mathrm{Cs}$, and other tracers: problems due to postdepositional mobility or coring artifacts. Canadian Journal of Fishery and Aquatic Science 44:231-250.

Blomqvist, S., 1991. Quantitative sampling of soft-bottom sediments: problems and solutions. Marine Ecology Progress Series 72:295-304.

Blomqvist, S. and B. Abrahamsson, 1985. An improved Kajak-type gravity core sampler for soft bottom sediments. Schweizerische Zeitschrift für Hydrologie 47:81-84.

Chant, L. and R. J. Cornett, 1991. Smearing of gravity core profiles in soft sediments. Limnology and Oceanography 36:1492-1498.

Cornett, R. J. and L. Chant, 1993. Comment on "Core compression and surficial sediment loss of lake sediments of high porosity caused by gravity coring". Limnology and Oceanography 38:695-699.

Crusius, J. and R. F. Anderson, 1991. Core compression and surficial sediment loss of lake sediments of high porosity caused by gravity coring. Limnology and Oceanography 36:1021-1031. 
Glew, J. R., 1991. Miniature gravity corer for recovering short sediment cores. Journal of Paleolimnology 5:285-287.

Hongve, D. and A. H. Erlandsen, 1979. Shortening of surface sediment cores during sampling. Hydrobiologia 65:283-287.

Huttunen, P. and J. Meriläinen, 1978. New freezing device providing large unmixed sediment samples from lakes. Annales Botanici Fennici 15:128-130.

Klee, R. and R. Schmidt, 1987. Eutrophication of Mondsee (Upper Austria) as indicated by the diatom stratigraphy of a sediment core. Diatom Research 2:55-76.

Lamoureux, S. F., 1994. Embedding unfrozen lake sediments for thin section preparation. Journal of Paleolimnology 10:141-146.

Lotter, A. F. The recent eutrophication of Baldeggersee (Switzerland) as assessed by fossil diatom assemblages. The Holocene: in press.

Lotter, A. F., M. Sturm, J. L. Teranes and B. Wehrli, 1997. Varve formation since 1885 and highresolution varve analyses in hypertrophic Baldeggersee (Switzerland). Aquatic Sciences 59: $304-325$.

Merkt, J., 1971. Zuverlässige Auszählungen von Jahresschichten in Seesedimenten mit Hilfe von Gross-Dünnschliffen. Archiv für Hydrobiologie 69:145-154.

Miskimmin, B. M., P. J. Curtis, D. W. Schindler and N. Lafaut, 1996. A new hammer-driven freeze corer. Journal of Paleolimnology 15:265-269.

Pachur, H.-J., H.-D. Denner and H. Walter, 1984. A freezing device for sampling the sedimentwater interface of lakes. Catena 11:65-70.

Parker, W. R. and G. C. Sills, 1990. Observation of corer penetration and sample entry during gravity coring. Marine Geophysical Researches 12:101-107.

Pollingher, U., H. Ambühl and H. R. Bürgi, 1992. A new method for processing clay-rich unconsolidated sediments for paleoecological investigations. Journal of Paleolimnology 7:95-101.

Renberg, I., 1981. Improved methods for sampling, photographing and varve-counting of varved lake sediments. Boreas 10:255-258.

Renberg, I., 1991. The HON-Kajak sediment corer. Journal of Paleolimnology 6:167-170.

Renberg, I. and H. Hansson, 1993. A pump freeze corer for recent sediments. Limnology and Oceanography 38:1317-1321.

Schaller, T., C. Moor and B. Wehrli, 1997. Sedimentary profiles of Fe, Mn, V, Cr, As and Mo recording signals of changing deep-water oxygen conditions in Baldeggersee. Aquatic Sciences 59:345-361.

Segerström, U. and I. Renberg, 1986. Calculating net annual accumulation rates of sediment components exemplified by pollen. Hydrobiologia 143:45-47.

Shapiro, J., 1958. The core-freezer - a new sampler for lake sediments. Ecology 39:748.

Wright, H. E., 1980. Coring of soft lake sediments. Boreas 9:107-114.

Wright, H. E., 1990. An improved Hongve sampler for surface sediments. Journal of Paleolimnology 4:91-92.

Received 8 January 1997;

revised manuscript accepted 17 July 1997. 